\title{
Static and dynamic behaviour of ECAPed copper alloy
}

\author{
Yerim Lee ${ }^{1}$, Keunho Lee ${ }^{1}$, Sanghyun $\mathrm{Woo}^{2}$, Changsoo Lee ${ }^{1}$, Leeju Park $^{1,2, *}$ \\ ${ }^{1}$ Agency for Defense Development, 34186 Daejeon 305-600, Republic of Korea \\ ${ }^{2}$ Weapon Systems Engineering, Korea University of Science and Technology, 34113 Daejeon, Republic of Korea
}

\begin{abstract}
The equal channel angular processing (ECAP) is a severe plastic deformation technique which can produce ultrafine-grained (UFG) alloy. This paper investigate the static and dynamic behaviour of ECAPed OFHC-Cu to evaluate possibility of its application to defence industries. Tensile tests were carried out at two different strain rate (10-3/s, 1/s) using digital image correlation (DIC) technique. High strain rate experiments were conducted using the split Hopkinson pressure bar (SHPB). The results were compared with forged OFHC-Cu and additional heat treated OFHC-Cu after processed by ECAP. Flow stress and strain sensitivity of ECAPed OFHC-Copper were increased compare to forged OFHC-Copper. After ECAPed copper heat treatment, the yield strength decreased with increasing of the average grain size. And numerical simulation of ECAPed copper shaped charge was performed using Autodyn hydrodynamic code.
\end{abstract}

\section{Introduction}

Ultra-fine-grained (UFG) and nanocrystalline materials have unique mechanical properties like strength, hardness due to grain refinement that have been the subject of extensive research. There is a significant jump in the strength of UFG copper in going from quasi-static to dynamic strain rate tests which is indicative of highstrain-rate sensitivity [1-3]. Although the research on the mechanical behaviour of ultra-fine-grained copper alloy has been reported, lots of issues remained. To evaluate possibility of ECAPed copper application to shaped charge liner, mechanical properties have to evaluate.

It is well known that the mechanical properties and dynamic behaviour of most materials depends on applied strain rate. After Kolsky [4] introduced the split Hopkinson pressure bar (SHPB) technique for dynamic testing of specimens, it has become a widely used experimental technique to test the materials at high strain rates. In order to obtain the basic data of dynamic properties, dynamic compression tests were conducted on a copper alloys by using a split Hopkinson pressure bar at a strain rate of $10^{3}$ order. The test results were compared with the quasi-static, intermediate strain rate results. The tensile results obtained using Digital Image Correlation (DIC) of the high-speed microphotographs. The results of the experimental work reported here were used to define a new set of material constants for the strength component of the Johnson-Cook model for ECAPed OFHC copper.

L. J. Park [5] performed study on the strain behaviour of the ECAP copper through DTE test at high strain rate. The results showed that ductility of UFG cooper was $437 \%$. It is reasonable result compared with the ductility of coarse grain copper (592\%). It seems that UFG copper can use shaped charge liner. Before penetration test, numerical simulation was conducted. Johnson-Cook model is being used in the Autodyn code. A critical component of the code is a validated material model parameters that can adequately represent the penetration.

\subsection{Johnson-Cook material model}

Various flow stress models have been suggested to represent the effect of the strain, the strain rate, and the temperature on the hardening properties of materials. In this study, one of the well-known models the JohnsonCook material model used.

Johnson and Cook (1983) proposed a dynamic hardening model that is capable of representing the effects of the strain, the strain rate, and the temperature on the flow stress of metallic materials as follows:

$$
\sigma=\left[\mathrm{A}+\mathrm{B} \varepsilon^{n}\right]\left[1+C \ln \frac{\dot{\varepsilon}}{\dot{\varepsilon}_{0}}\right]\left[1-\left(\frac{T-T_{r}}{T_{m}-T_{r}}\right)^{m}\right]
$$

where $\varepsilon$ is the equivalent plastic strain, $\frac{\dot{\varepsilon}}{\dot{\varepsilon}_{0}}$ is the plastic strain-rate, $\mathrm{Tr}$ and $\mathrm{Tm}$ are the reference temperature and the melting temperature of the material, respectively. And A, B, C, n, m are material constants.

\section{Experiments}

\subsection{Materials}

* Corresponding author: 1.jpark@add.re.kr 
The tested materials are three kinds of oxygen-free highconductivity (OFHC) Cu. Selected materials in this work are obtained through forging after cold-rolled, ECAPed OFHC and heat treated after ECAP Processing. Before conducting ECAP process, $\mathrm{Cu}$ rods were annealed 1 hour at the temperature of $900{ }^{\circ} \mathrm{C}$ to stabilize the microstructure and remove residual stress. After that, processed using a hydraulic machine in Fig1. The ECAP die with an interior channel angle of $105^{\circ} .16$ passes were processed using route $B_{C}$ to achieve ultrafine grained microstructure. In route $\mathrm{B}_{\mathrm{C}}$ the specimen is rotated $90^{\circ}$ in same direction between each pass. The experimental set-up was explain ref. [6]. And also, Additional heat treatment is conducted after ECAP process at $200{ }^{\circ} \mathrm{C}, 1$ hour to stabilize the microstructure. Because ECAP copper go through grain coarsening resulting from natural aging at room temperature [7].

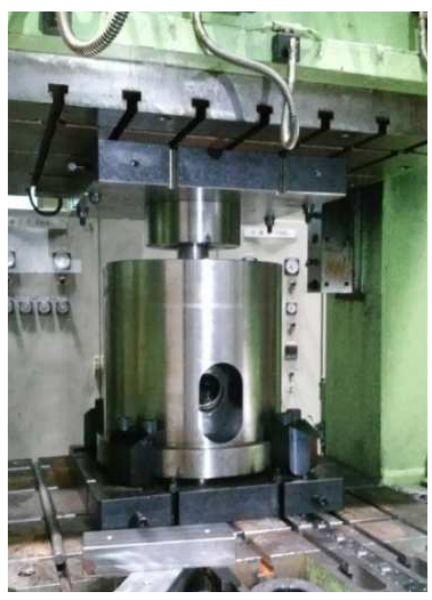

Fig. 1. ECAP die with 800ton press.

\subsection{Mechanical tests}

To investigate the static and dynamic behaviour of ECAPed OFHC-Cu, Uniaxial tensile tests and split Hopkinson pressure bar tests were conducted. Quasistatic state (001 s-1) and dynamic material test at intermediate strain rate $(1 \mathrm{~s}-1)$ tensile tests were performed using a MTS810 universal machine with a maximum load capacity of $25 \mathrm{KN}$. After testing the images are processed using a Digital Image Correlation (DIC) technique.

A split Hopkinson pressure bar was used for high strain rate experiments. A projectile (striker bar) impacts the incident bar, producing in it a pulse with a length that is large with respect to the specimen. This elastic wave travels through the incident bar and then reaches the specimen, which is sandwiched between the incident and the transmitted bar. The amplitude of the wave is such that plastic deformation is imparted to the specimen [8].

\subsection{Numerical simulation}

In this study, OFHC copper processed by ECAP process Shaped Charge (SC) was numerically simulated using the Autodyn 2D axisymmetric hydrodynamic code.
Johnson-Cook material model was adapted, JC Parameters were get through the mechanical tests. Fig.2 shows the numerical model of the shaped charge consist of OFHC-Cu liner, Al7075 and Al2024 case, DXC-59 explosive. The charge diameter used to numerical simulation is $95 \mathrm{~mm}$, liner diameter is $80 \mathrm{~mm}$. First, to investigate liner behaviour, Eulerian model was used. And then penetration behaviour of SC jet was concerned using Lagrange model. The target used mild steel (diameter $50 \mathrm{~mm}$, length $600 \mathrm{~mm}$ ) (Fig.3).

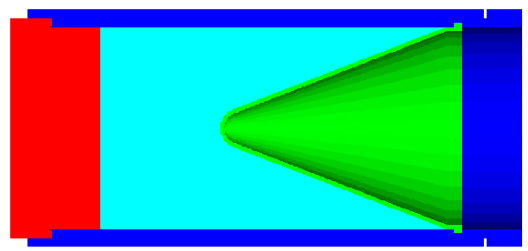

Fig. 2. Numerical model of SC.
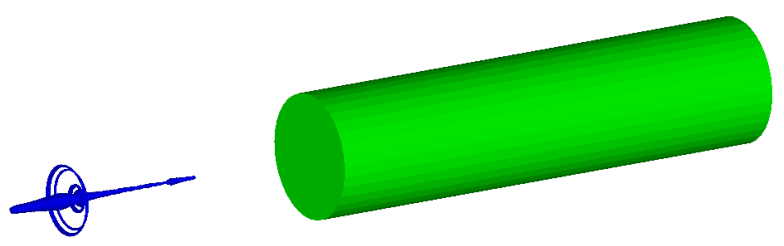

Fig. 3. Numerical model of shaped charge jet and target.

\section{Results and discussion}

\subsection{Microstructure}

Fig.4 gives the metallographic micrographs of forged OFHC copper, 16 pass ECAP copper and heat treated copper after ECAP process. The grain size of forged copper is about $80 \mu \mathrm{m}$. ECAPed copper has less than 1 $\mu \mathrm{m}$ of grain size, and It can be seen most equiaxed grains. Comparison of the two images shows the grain refinement obtained by ECAP process. In the Fig. (c), Similar with forged microstructure were observed but coarse size of microstructure than it (about $5 \mu \mathrm{m}$ ). The equiaxed microstructure was disappeared. It seems to be additional heat treatment cause recovery and recrystallization of copper. Fig. 5 shows hardness results of thermal treated copper at $200{ }^{\circ} \mathrm{C}$. Before $1000 \mathrm{~s}$, the microstructure partially recrystallized and then after $1000 \mathrm{~s}$, hardness was decreased significantly because of perfectly recrystallization. 


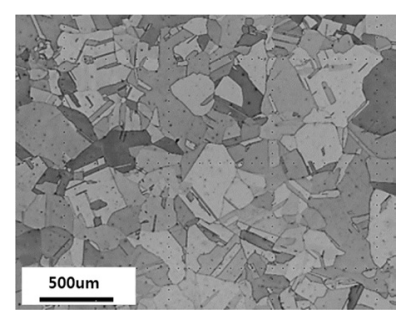

(a)

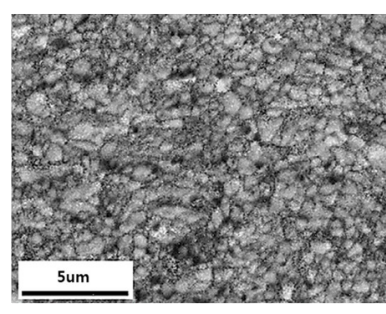

(b)

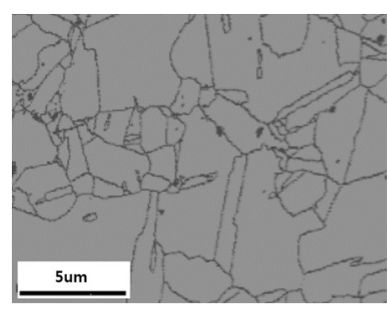

(c)
Fig. 4. Microstructure of (a) Forged OFHC copper, (b) ECAPed OFHC copper, (c) $200{ }^{\circ} \mathrm{C}, 1 \mathrm{~h}$ heat treated OFHC copper after ECAP process.
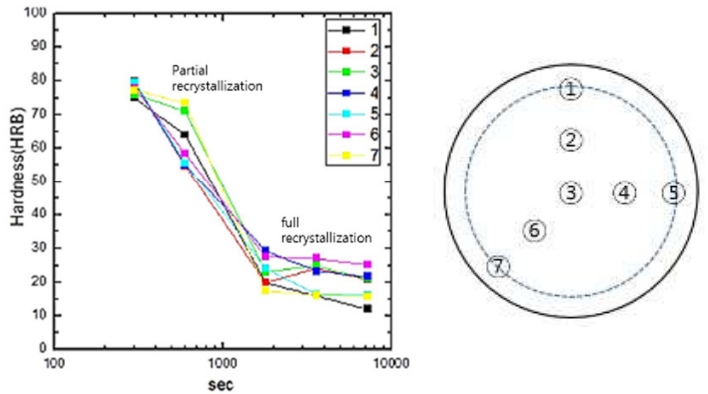

Fig. 5. Hardness result of $1 \mathrm{~h}$ heat treated OFHC copper after ECAP process.

\subsection{Mechanical properties}

Results from the Quasi-static state $\left(001 \mathrm{~s}^{-1}\right)$, intermediate strain rate $\left(1 \mathrm{~s}^{-1}\right)$ tensile tests and dynamic compression tests carried out at a strain rate of $10^{3}$ order are plotted in Fig. 6. Under the quasi-static loading, the forged OFHC copper shows the yield strength of $173 \mathrm{MPa}$, the ECAPed OFHC copper shows the higher yield strength (434 MPa). The yield stress and flow stress of the ECAPed copper higher than forged copper since the grain size is reduced into ultrafine grain. It can be explained classical Hall-Petch relationship. The results of strain rate at $1 / \mathrm{s}$ shows similar value with quasi-static strength. In both copper alloy, the dynamic strength is higher than the quasi-static one according to strain rate strengthening effect [9-11]. The results of heat treated copper alloy shows similar yield strength and flow stress with forged copper at strain rate $0.001 / \mathrm{s} 1 / \mathrm{s}$. Also under the high strain rate state, strength is decreased compare with ECAPed copper. This is the reason of recrystallization of equiaxial grains as described earlier. In case of ECAPed copper, there was a significant increase in strength at high-strain rate as compared to the quasi static tests. Because UFG metals are known to have a higher strain-rate sensitivity than their coarsegrained counterpart. Generally, the strain rate sensitivity increase with grain refinement on the face-centred cubic (FCC) metals [12].

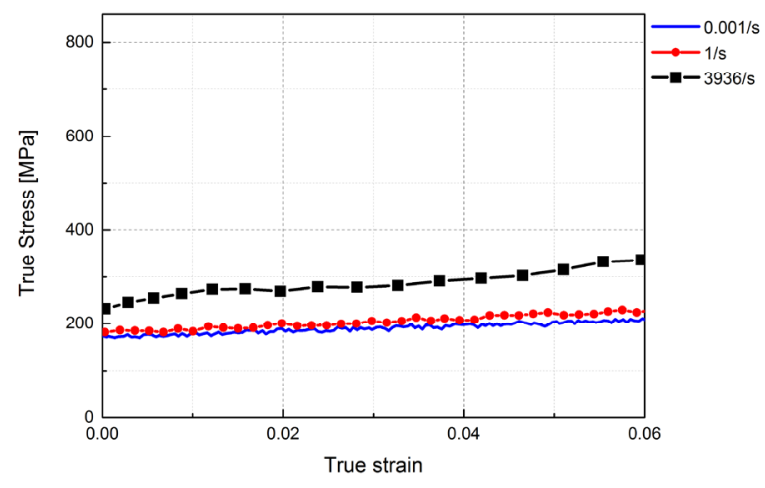

(a)

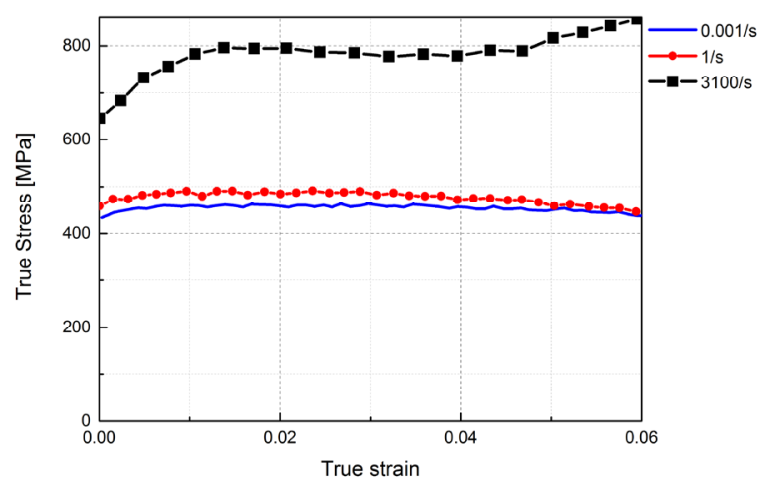

(b)

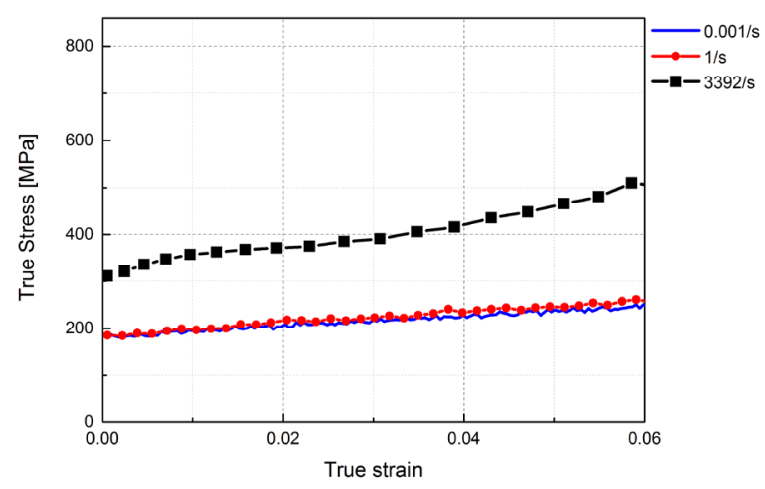

(c)

Fig. 6. True stress-strain curves of OFHC copper at different strain rates (a) Forged OFHC copper, (b) ECAPed OFHC copper, (c) $200{ }^{\circ} \mathrm{C}, 1 \mathrm{~h}$ heat treated OFHC copper after ECAP process. 


\subsection{Results of numerical simulation}

Table1 shows the material coefficients for Johnson-Cook model of ECAPed $\mathrm{Cu}$. It obtained by JC fitting with strain rate $1 / \mathrm{s}$ (reference strain rate), 3100 /s true StrainStress curve (Fig.7).

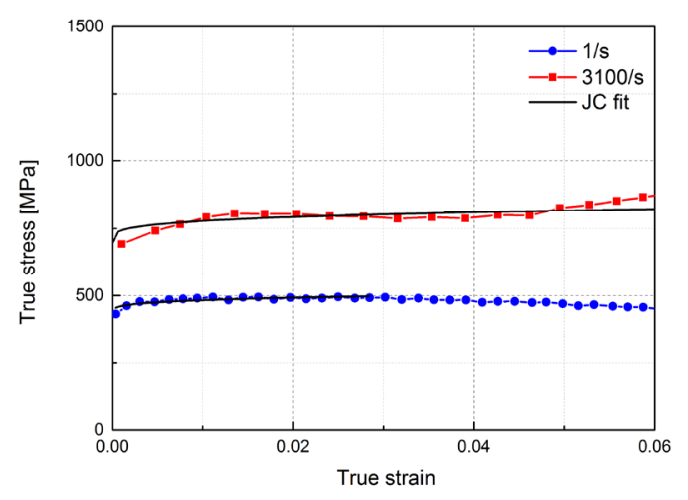

Fig. 7. Johnson-Cook fitting with True stress-strain data.

Table 1. ECAPed OFHC-Cu JC Parameters (ref. strain rate: $1 / \mathrm{s})$.

\begin{tabular}{|c|c|c|c|c|}
\hline $\mathrm{A}$ & $\mathrm{B}$ & $\mathrm{n}$ & $\mathrm{C}$ & $\mathrm{m}$ \\
\hline 432.01 & 154.9 & 0.241 & 0.076 & 1.09 \\
\hline
\end{tabular}

By the Autodyn 2D code, numerical simulation was conducted. Fig. 8 is the penetration result of ECAPed copper shaped charge liner which penetrated depth is about $500 \mathrm{~mm}$. It is accordance with forged copper liner penetration test result we already carried out before.

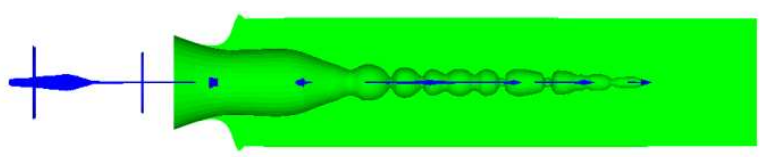

Fig. 8. penetration feature according to the JC model at $2 \mathrm{CD}$.

\section{Conclusions}

In the present work, the quasi-static, intermediate strain rate tensile test and dynamic compression test have been conducted to investigate copper alloys mechanical properties. The deformation applied to the copper by ECAP processing results in a grain refinement. It has caused a strength increase of copper alloy in both static and dynamic tests. And also, grain refinement result in to the increase of strain rate sensitivity. However, the yield stress and rate sensitivity of heat treated ECAP copper has decreased as before ECAP process. Additional heat treatment has led grain coarsening and that is why $200^{\circ} \mathrm{C}$, 1hour is inappropriate process condition. We need to find suitable heat treatment temperature and time.

Also, to investigate the possibility of application of ECAPed copper to shaped charge liner, numerical simulation was conducted. Using Autodyn code shaped charge penetration behaviour was analysed. On the basis of mechanical test results, JC parameters were get and it was adapted material model. The penetration result was considerably reasonable. We proved positive possibility of application of ECAPed copper to shaped charge liner. The following study will compare simulation results with penetration experiment result.

\section{References}

1. Gleiter H. Prog Mater Sci 33, 223-315 (1989)

2. J. Weertman, Nanostructured materials, p. 393-417 (2002)

3. M. A. Meyers, A. Mishra, DJ. Benson, Prog Mater Sci, 51, 427-556 (2006)

4. H. Kolsky, Proc. Phys. Soc. London, Sect. B, 62, pp. 676-700 (1949)

5. L. J. Park, H.J. Kim, S.B. Kim, 11th International conference on the mechanical and physical behaviour of materials under dynamic loading, 2011 (2015)

6. A. Mishra, B.K. Kad, F. Gregori, M.A. Meyers, Acta Mater, 55 (2007)

7. Y. Estrin, N.V. Isaev, S.V. Lubenets, S.V. Malykhin, A.T. Pugachov, V.V. Pustovalov, et al. Acta Mater 54, 5581 (2006)

8. M.A. Meyers, Dynamic behaviour of materials, (1994)

9. A. Uenishi, C. Teodosiu, E.V. Nesterova, Mater. Sci. Eng. A 400-401 (2005)

10. H. Huh, J.H. Lim, S.H. Park, Int. J. Automot. Technol. 10 195-204 (2009)

11. J.H. Chung, J.K. Park, T.H. Kim, K.H. Kim, S.Y. Ok, Mater. Sci. Eng. A 5072-5077 (2010)

12. Q. Wei, J. Mat. Sci. Eng. A 375, 46-52 (2004) 